This item was submitted to Loughborough's Research Repository by the author.

Items in Figshare are protected by copyright, with all rights reserved, unless otherwise indicated.

\title{
Reframing egg donation in Europe: new regulatory challenges for a shifting landscape
}

PLEASE CITE THE PUBLISHED VERSION

https://doi.org/10.1016/j.hlpt.2020.04.007

\section{PUBLISHER}

Elsevier

\section{VERSION}

AM (Accepted Manuscript)

\section{PUBLISHER STATEMENT}

This paper was accepted for publication in the journal Health Policy and Technology and the definitive published version is available at https://doi.org/10.1016/j.hlpt.2020.04.007.

\section{LICENCE}

CC BY-NC-ND 4.0

\section{REPOSITORY RECORD}

Hudson, Nicky, Lorraine Culley, Cathy Herbrand, Vincenzo Pavone, Guido Pennings, Veerle Provoost, Katie Coveney, and Sara Lafuente Funes. 2020. "Reframing Egg Donation in Europe: New Regulatory Challenges for a Shifting Landscape”. Loughborough University. https://hdl.handle.net/2134/12603227.v1. 


\title{
Reframing egg donation in Europe: new regulatory challenges for a shifting landscape
}

\begin{abstract}
The first birth from a donated egg was reported in Australia in 1984, ushering in a new era of possibilities for the treatment of infertility (1). Since then egg donation has undergone a number of technical, regulatory and commercial transformations. Its use by a growing and diverse range of social groups and more recently the dawn of advanced freezing technologies, have reconfigured the process. Given the transformation in its organisation and practice, there is a pressing need to map these changes in finer detail and to ask critical questions about the continued fit of existing policy and regulation in this rapidly developing landscape of fertility medicine. In this paper we present a 'critical reflection' (2) on developing practices in egg donation, which we suggest are reshaping the character of egg donation as well as raising questions regarding their implications for policy. We highlight a number of policy 'blind-spots' relating specifically to information giving and informed consent for egg providers, the emergence and entry of a range of intermediaries and a shift towards certain practices which may see eggs increasingly treated as tradable commodities. We call for a re-contextualising of the debate on egg donation and for renewed attention to the new political economy of egg donation in Europe.
\end{abstract}

\section{Introduction}

The first birth from a donated egg was reported in Australia in 1984, ushering in a new era of possibilities for the treatment of infertility (1). Egg donation was first developed so that those who had experienced infertility or premature menopause could experience gestational motherhood (3). The process typically involved one woman - who was usually also undergoing infertility treatment herself providing eggs to another woman (1). IVF was still in its infancy at the time, with only 15 IVF babies born between 1978 and 1983, and egg donation remained confined to a small number of specialist medical centres (4). Since then egg donation has undergone a number of technical, regulatory and commercial transformations. Its use by a growing and diverse range of social groups, the emergence of a global patchwork of donor identification and compensation practices, and more recently the dawn of advanced freezing technologies have reconfigured the process. Over thirty-five years later, egg 
donation is routinely offered as a means to overcome unwanted childlessness. Given the transformation in its organisation and practice, there is a pressing need to map these changes in finer detail and to ask critical questions about the continued fit of existing policy and regulation in this rapidly developing landscape.

In this paper, we highlight the need to give greater emphasis to the new political economy of human eggs (5) and specifically call for a renewed focus on the practice and growing commercialisation of egg donation in the European context for a number of reasons. First, egg donation has been underexplored in the European context, despite the high number of egg donation cycles which take place annually. Second, whilst recent attention has been afforded to the development, application and commercialisation of novel reproductive techniques such as egg freezing for 'social' reasons and techniques such as mitochondrial donation, we suggest that broad scale and significant changes to the character of more established fertility treatments such as egg donation have been overlooked. Finally, within the EU (European Union) egg donation is governed at the supra-national level by the EU Tissue and Cells Directive (2004/23/EC) (6), which requires that the 27 EU member states can only procure and process human eggs (and other tissues and cells) for therapeutic purposes if explicit commercialisation is avoided. Each individual country within the EU draws on this framework to inform national policy on egg donation, and whilst in theory this means that all countries are required to avoid commercialisation, local practices and cultures mean that this requirement is implemented variably. For example, some countries have enacted explicit laws relating to profit-making activity (e.g. a longstanding law in Belgium which outlawed the use of clinic-specific advertising to recruit donors), others appear to have permitted a more commercialised approach to develop (for example the emergence of commercial egg banks in Spain). In addition, one study of egg donation in 11 European countries showed that no one country applied the same rules regarding the compensation of egg donors (7). Despite such variations, the EU Directive provides a unique set of principles within which ART (assisted reproductive technologies) can be employed; providing a valuable opportunity to consider the relationship between science policy and medical practice more broadly (8).

In this paper we present a 'critical reflection' (2) on developing practices in egg donation, which we suggest are reshaping the character of egg donation as well as raising questions regarding their 
implications for policy. We begin by providing a brief description of the recent expansion in use of donor eggs in the European context, before presenting three specific changes to practice: increases in egg freezing; the growth of egg intermediaries; and changes to the genetic screening of donors. In each case, we discuss what we see as the associated implications and challenges for wider policy actors and processes, including (but not limited to) the EU Directive. We conclude by drawing attention to what we suggest are a number of resulting policy 'blind spots' regarding egg donation in Europe.

\section{Context: the expansion of egg donation in Europe}

The global expansion of the use of donor eggs has been exponential. Since its first use in 1984, demand for egg donation has increased year on year and the technique now accounts for $6 \%$ of all cycles of IVF globally (9). Europe has recently emerged as the largest regional provider of egg donation, with over 56,000 cycles (constituting $7 \%$ of treatment cycles) carried out annually (10). Spain alone accounts for $54 \%$ of cycles in Europe, leading it to be dubbed the 'egg donation capital' of Europe.

This growth in use of donor eggs in part reflects a changing profile amongst users as access to the treatment has diversified. Increasing birth rates amongst women over 40 in many western countries represent a considerable contribution to the growth in the use of donor eggs (11). It has been suggested that there is a growing tendency towards earlier use of third-party eggs in a patient's treatment journey in order to improve success rates, especially for older women (12). Donor eggs are also recommended where there may be a risk of passing on an X-linked condition, such as haemophilia, to offspring or in the context of infertility due to genetic disease, as with Turner Syndrome. The use of third-party eggs is also increasing in the context of allied reproductive technologies - for example in the case of gestational surrogacy, where neither the gestating woman nor the intended mother is the egg provider. If rolled out more widely, controversial techniques such as mitochondrial donation for age-related fertility decline (a technique originally developed to prevent the transmission of maternally inherited mitochondrial disorders) will also require a constant supply of donor eggs (13). Increasing levels of 'reproductive tourism' in recent years have also driven the demand for eggs as people travel to places where eggs are more easily available (14). 
Growing demand from a range of sources requires a sustained supply of eggs. Supply is shaped by a number of social and political factors including the cultural framing of egg donation, local regulatory levers and specificities of clinical practice (15). High rates of rejection and screening out by clinics of what are considered to be unsuitable donors, reduces supply whilst simultaneously requiring large numbers of women to put themselves forward as candidates. Clinics make such selections according to a range of criteria including genetic profile, physical and mental health status and physical characteristics $(12,16-17)$. Increased demand for donors appears to have led to a growing number, and increasing novelty, of schemes offered by clinics to attract donors to service this growing demand e.g. 'freeze and share' (whereby women can freeze some of their eggs for their own later use free of charge if they also donate eggs) and fertility check ups, designed to give information about future fertility, for egg providers. Whilst these schemes themselves do not breach EU regulations, they may be indicative of a broader shift towards a growing economy around eggs in the European context.

The sustained growth in the demand for and use of donor eggs has received little critical attention or analysis in the European context, particularly with regards to any implications for its wider regulation (including for the women who provide eggs). As described above, the EU Tissue and Cells Directive requires that members avoid commercialisation (6). This has generally been interpreted as a requirement for member states to avoid the commercialisation of human gametes. In this paper we consider changes, which, we suggest may present a challenge to this requirement. We begin our critical reflection on the field with a discussion of the growing use of vitrification for the management and storage of eggs.

\section{Egg cells on ice: the growing use of vitrification}

As a recent technique for enabling the storage of eggs, vitrification has been discussed extensively in relation to autologous or 'social' egg freezing (whereby women store eggs for their own, later use (1820). However, the policy and practice implications of more effective methods of freezing for processes of egg donation have been relatively underexplored. The vitrification method represented somewhat of a breakthrough in the management of human eggs because it leaves eggs relatively unaffected by the process (21). As the largest cell in the human body, eggs have historically been difficult to freeze, unlike sperm or embryos, which have been frozen successfully for decades. It is, however, a 
specialized technology that requires a high level of experience and recent high success rates come from experienced teams (e.g. 22). Despite variation in uptake of the method between clinics, a general increase in the practice of freezing eggs is occurring across Europe (23-24). Whilst this upward trend in frozen egg cycles can in part be accounted for by the recent expansion in 'social' egg freezing, a large proportion of frozen eggs cycles are also due to the increase in their use in egg donation cycles (for example, almost 30 per cent of egg donation cycles in Spain used frozen eggs in 2017) (25).

Vitrification represents a considerable change in clinical practices associated with egg donation because it permits more flexibility over how eggs are managed. Prior to the development of vitrification, the use of fresh donor egg treatment meant that the cycles of egg provider and recipient needed to be synchronized so that fertilisation and embryo transfer could be carried out immediately after eggs were retrieved from the egg provider (in a similar way to its early use). The arrival of vitrification represented a potentially more attractive method for clinics because it avoids the need for donor and recipient to be synchronised, thereby reducing the possibility of cancelled treatment cycles $(5,21)$. Due to the earlier need for synchronisation, fresh egg treatment also usually restricted donation to a one-to-one model, or where more eggs were retrieved, one-to-two donation. However technical advances in freezing now make two things possible: the ability to freeze means that eggs retrieved from one donor can now be 'batched' and stored for later use in multiple patient cycles (i.e. more than 1 or 2); and a store of frozen eggs also means that more expedient recipient-provider matching, with greater choice of egg provider, can take place.

The ability to divide and store batches of eggs from one retrieval cycle shifts practice away from a model where certain eggs are allocated immediately to a chosen recipient and where other eggs, which remain after this first cycle, might become 'surplus'. In the batch-freezing model, the idea of surplus eggs becomes redundant because the eggs are always destined for more than one recipient. We suggest that greater consideration needs to be given to how eggs which are not immediately allocated to a recipient, but are frozen for later use, are managed in practice. If stored eggs aren't immediately allocated to a recipient, important questions are raised about who is making decisions about the future use of eggs. New practices related to the management of frozen eggs disrupt existing 
assumptions and prevailing cultural imaginaries routinely employed in much existing donor recruitment, which portray donation as (an immediate) woman-to-woman transfer and therefore as a unique and individual 'gift' $(12,26)$. We suggest that the potential provision of eggs from one retrieval cycle to multiple recipients raises important questions relating to donors' expectations and continued consent regarding the use of their eggs and to the potential for increased commercialisation from those eggs.

Vitrification also facilitates the import and export of eggs in a way that was only previously possible with frozen sperm and embryos. The ability to separate eggs from the woman who provided them in space and time makes it possible for clinics to procure and transport eggs internationally, potentially transforming the way eggs are managed globally (see 5). It also means that recipients are no longer required to travel abroad for egg donation treatment. Whilst this is an attractive option on the part of recipients and some clinics, the implications of this for donor consent and expectations about when and where their eggs are used need to be considered. These changes have considerable implications for the potential for profit-making practices relating to the procurement, storage and shipping of eggs between clinics.

Reproductive outsourcing? The emergence and rise of 'egg intermediaries' The growth in demand for eggs, coupled with the increasing flexibility afforded by freezing technologies, has seen an accompanying rise in the development of a range of 'egg intermediaries' in the European context. These organisations and individuals have two aspects in common: a role in the recruitment of egg providers; and (in most cases) relative independence from a fertility clinic, and therefore potential distance from direct medical accreditation and regulation. Whilst intermediaries have been historically more commonplace in commercialised settings such as the US, South Africa, India or Thailand, their presence has been less well-established in the European context, which has historically seen lower levels of outsourcing of reproductive services. Studies from the US have highlighted their use in marketing and recruitment (e.g. 5, 27), with some concerns raised about their quality and oversight (28). We include for consideration in our analyses: commercial egg banks; egg donation agencies and/or brokers; and direct egg provider-recipient connection services.

\section{Egg banks}


The emergence of commercial egg banks is a relatively recent phenomenon (29-30). As outlined above, the development of vitrification has transformed the management of eggs, permitting them to be successfully frozen and stored with little to no loss of quality allowing for extended periods of storage and their movement within and between national contexts. Commercial egg banks use this ability to operate in one of three ways: to provide eggs to a single affiliated clinic; to provide eggs to a group of affiliated clinics, or to provide eggs to any interested clinics (31).

Whilst slower to emerge in Europe than in places such as the US (results from a first egg bank were reported in the US in 2007 (32)), there is increasing evidence of their existence (both 'in-house' and independent egg banks) in Europe, illustrating a growing willingness to invest in the expertise, equipment and facilities needed for set up (5). However, so far there has been little debate about their emergence or about the implications of their operation on the field. Where such entities may be utilising eggs retrieved from one cycle for more than one recipient, profit can be generated beyond the recovery of the costs of the original cycle, raising questions relating to the direct generation of profit from supernumerary eggs (i.e. potentially challenging aspects of the EU Directive).

The operation of egg banks (whether in-clinic or external), also raises questions of on-going decisionmaking and future consent if eggs are not immediately allocated to a recipient. This has particular ramifications for egg providers in contexts where they are required to be identifiable in future if families are created over a much longer time period than was the case with fresh egg cycles.

\section{Egg agencies and brokers}

Egg agencies and brokers are amongst the most well-established form of egg intermediary (17). They typically focus on the recruitment of egg providers, allowing clinics to outsource the complexity and challenges associated with meeting greater demand for eggs. Where local regulations allow for targeted recruitment, they also facilitate the enrolment of egg providers who have traditionally been harder to reach (e.g. from minority ethnic groups). Because agencies and brokers do not directly manage human tissue, they tend to operate outside of the regulatory contexts in which European clinics (and most egg banks) would find themselves meaning there is limited oversight and monitoring (33). Whilst some brokers and agencies work directly for clinics, others offer their services directly to recipients, in some cases charging a fee for mediation or support (33). In a context of growing 
demand, we may continue to see the emergence of a range of intermediaries carrying out a diverse range of recruitment activity within Europe. However, their existence adds further weight to longstanding questions relating to inequality and stratification in access, since only those who are in a financial position to do so can pay their often very high fees. As others have suggested, an increase in their operation may also signal a shift towards growing commercialisation in the field more generally (5).

\section{Direct connection services}

This group of intermediaries are distinct in that they offer a means for egg providers and recipients who are previously unknown to one another, to make direct contact prior to donation. Often positioned as on-line portals, forums, or in some cases, speed-dating events (34), they offer a space where egg providers can meet egg recipients (or for people looking for co-parenting arrangements). They generally offer a relatively 'light touch' approach to facilitation, marketing themselves as a service whereby users meet and then go on to create relationships in preparation for the donation (or in the case of co-parenting, the parenthood) process itself. Unlike in the case of home insemination with donor sperm, with egg donation a clinic is subsequently needed to facilitate treatment with donor and recipient presenting at the clinic as having an existing relationship. Direct connection services can therefore only operate in regulatory contexts where known donation is permitted, such as the UK and Belgium. These intermediaries are unique in that they operate outside of more formalised, institutional and in some cases commercial settings. They trouble the existing formalised boundaries around categories such as known donation, ID-release donation and co-parenting (34), allowing recipients and providers agency to circumvent existing regulations and categories and to engage in more novel forms of procreation.

The implications of each of the above types of intermediaries for egg donation policy deserves closer scrutiny. They pose important questions related to their practice, governance and oversight. For example, how does their work interface with existing clinic-based models of recruitment? What are the legal responsibilities of such entities? Should they be regulated by nation states, paving the way to a greater variety of regimes and a lack of common principles on egg donation? Or should the EU provide common and possibly exhaustive oversight, and protect donors regardless of where they 
donate, but at the cost of disregarding the cultural, social and political peculiarities of individual countries? Finally, it is important to consider if and how intermediaries present a challenge to EU regulation on the non-commercialisation of human tissue.

\section{New forms of genetic 'matching' - expanded carrier screening in egg donation}

The EU Tissue and Cells Directive/17/EC (annex III) (2006) (35) states that providers of reproductive cells must be screened for genetic and medical risks. Routine screening is typically performed through genetic family history questionnaires which enable the identification of diseases or disorders with a clear heritable link, with uncertain cases requiring further genetic testing. Gamete providers from particular ethnic groups may also be required to undergo additional carrier screening, due to the prevalence of particular conditions within certain communities (36). On this basis, a candidate may be considered unsuitable and rejected by the clinic. Despite these measures, however, there have been a series of high profile cases in which serious genetic conditions have been identified after gamete donation has taken place, and which could have been inadvertently passed from donor to offspring signifying the potential for 'genetic risk' in donor conception (37).

Newer screening techniques now allow for a much wider range of pre-conception genetic screening practices than has historically been possible, with providers stating that they increase the chance of a risk-free conception. Expanded screening differs from traditional carrier screening in that it involves the possibility to screen individuals for hundreds of diseases - most with lower incidence or severities than are usually included in routine standard carrier screening (38). The tests include analysing a sample of blood or other biological material for evidence of genetic mutations associated with autosomal-recessive and X-linked conditions. This method also permits screening of a pan-ethnic population; i.e. screening takes place regardless of pre-determined risk factors associated with ethnic group membership or ancestry.

Current professional and ethical debate has highlighted the increased need for genetic counselling implied by expanded carrier screening (ECS), whereby donors who are identified as having a genetic mutation may need specialist counselling. However, clinics may not have routine access to specialist counselling (39). Egg providers may feel compelled to comply with the screening, especially in a context in which they are financially compensated. ECS also presents the possibility that donors can 
be selected and de-selected according to very specific genetic health profiles, allowing for the possibility of a hierarchy of egg providers whereby certain candidates are identified as mutation or 'disease' free and therefore more attractive to recipients (38). The use of ECS is beginning to emerge as routine practice in some European contexts (e.g. some clinics in Spain), whilst elsewhere, it has yet to be implemented in routine practice due to the additional cost for patients and additional in-clinic resources (such as counselling).

There is growing evidence of a drive towards ECS within the ART sector as an increasing number of panels are developed (40) and is representative of a burgeoning interest in genetic 'add ons' more generally. However, a lack of professional guidance or specific regulation on ECS in Europe means that clinics are effectively operating in a policy vacuum, thereby creating the potential for an in-country market if clinics offer differing screening services (factors which also apply in sperm donation). ECS may also catalyse new forms of reproductive tourism from Europe to the US or within Europe to places like Spain, thereby further entrenching inequality in access to services within the European context.

\section{$\underline{\text { Conclusion }}$}

As trends in contemporary family-building continue to shift, egg donation, along with other ARTs, has increasingly diversified. Developing from a relatively marginal addition to IVF treatment at its inception, the use of third party eggs has enabled the parenthood desires of the growing number of women over 40 (and their partners) seeking treatment for age-related infertility, as well as enabling gay male couples and those rendered infertile via genetic disease to become parents. Growing demand means that clinics need to find new ways to attract candidate donors and to ensure maximum efficiency in the treatment process. Specific developments relating to the freezing and storage of eggs, the development of a range of intermediaries, and the use of new techniques for screening providers, we suggest, represent significant transformations in the growing use of third party eggs; changes which are radically 're-tooling' the ART landscape (41).

Such changes require a substantial investment in logistics, technologies and staff meaning that clinics are required to find new ways to expand provision and may constitute a move towards greater 
commercialisation, which requires urgent policy attention. Whilst private clinics have long existed as commercial actors seeking profit in exchange for the offer of medical services, the social security tradition in health care in most of Europe has traditionally operated as a moderating factor in the move to full commercialisation. However, a reduction in public funding in some countries (e.g. the UK) in recent years has contributed to this privatised landscape as government-funded fertility treatment becomes increasingly scarce. The specificities of the European policy context have also historically acted as a constraint on explicit forms of profit-making from human tissue. However, an increasingly blurred distinction between private/public services, regulated/unregulated actors and commercial/noncommercial practice is muddying the water and has, we suggest, left the sector relatively free to pursue more explicit commercial approaches, which we suggest are worthy of critical attention.

Questions about the commercialisation of extractable tissue (including blood and sperm) within the EU context have existed for a number of years, though they remain relatively under-developed (42). We suggest therefore that the case of egg donation presents a renewed opportunity to directly address these questions. Whilst there are similarities with other kinds of tissue (particularly sperm), we suggest there are a number of ways that the procurement and management of eggs is distinct. This relates primarily to the limited evidence base about the long-term health risks of egg extraction for women's health, about which there is still limited evidence, meaning that there are potential risks for the thousands of women recruited into a rapidly expanding tissue economy. There also exists a need for greater attention to the particular (gendered) ways in which egg donation is marketed to women as a form of woman to woman solidarity. This is potentially problematic when considering the changing practices around the distribution of eggs and the growing diversification of recipients. Both of these factors raise questions about women's informed consent for this particular form of tissue extraction.

We propose that changes to the landscape and practice of egg donation have created a number of policy 'blind-spots' relating specifically to information giving and informed consent for egg providers, the emergence and entry of a range of intermediaries and a move towards certain practices which may see eggs increasingly treated as tradable commodities. We therefore call for a re-contextualising of the debate on egg donation (which is often focused on the needs and experiences of egg 
recipients) and for renewed attention to the new political economy of egg donation in Europe; something which has been largely invisible. This would entail increased public debate and dialogue between a range of stakeholders, improved policy consultation with egg providers and their advocacy organisations and better understanding of the ways in which governance processes are implemented locally. In relation to EU regulation this could include increased specificity in the parameters of 'forprofit' activity, a debate about who is permitted to gain financially from the extraction and processing of eggs, and the implications for other forms of tissue, including sperm. Assuming that noncommercialisation remains a shared objective, an appraisal of EU regulation would in turn imply that countries be required to review their own practices, laws and governance. A renewed emphasis on tissue economies would also ensure that policy-making keeps step with technological and commercial changes, and that questions such as access, equity, and consent are central features of ART policy decision-making. 


\section{References}

(1) Sauer MV. Revisiting the early days of oocyte and embryo donation: relevance to contemporary clinical practice. Fertil Steril. 2018;110(6);981-7. doi: 0.1016/j.fertnstert.2018.09.005

(2) Hauskeller C, Beltrame L. Hybrid practices in cord blood banking. Rethinking the commodification of human tissues in the bioeconomy. New Genet Soc. 2016;35(3);228-45. doi: 10.1080/14636778.2016.1197108

(3) Lutjen P, Trounson A, Leeton J, Findlay J, Wood C, Renou P. The establishment and maintenance of pregnancy using in vitro fertilization and embryo donation in a patient with primary ovarian failure. Nature. 1984;307(5947);174-5.

(4) Trounson A, Leeton J, Besanko M, et al. Pregnancy established in an infertile patient after transfer of a donated embryo fertilised in vitro. Br Med J (Clin Res Ed). 1983;286(6386);835-8. doi: $10.1136 / \mathrm{bmj} .286 .6368 .835$

(5) Waldby C. The oocyte economy: the changing meaning of human eggs. Durham; Duke University Press; 2019.

(6) Directive 2004/23/EC of the European Parliament and of the Council of 31 March 2004 on setting standards of quality and safety for the donation, procurement, testing, processing, preservation, storage and distribution of human tissues and cells. Official Journal of the European Union L $102 / 48$.

(7) Pennings G, de Mouzon J, Shenfield F, Ferraretti AP, Mardesic T, Ruiz, A Goossens V, Sociodemographic and fertility-related characteristics and motivations of oocyte donors in eleven European countries, Human Reproduction, 2014; 29(5); 1076-1089.

Doi: https://doi.org/10.1093/humrep/deu048

(8) Hoeyer K. An anthropological analysis of European Union (EU) health governance as biopolitics: the case of the EU tissues and cells directive. Soc Sci Med. 2010;70(12);1867-73. doi: 10.1016/j.socscimed.2010.02.040

(9) Adamson DG, De Mouzon J, Chambers GM, et al. International Committee for Monitoring Assisted Reproductive Technology: world report on assisted reproductive technology, 2011. Fertil Steril. 2018;110(6);1067-80. doi: 10.1016/j.fertnstert.2018.06.039

(10)De Geyter C, Calhaz-Jorge C, Kupka MS, et al. ART in Europe, 2014: results generated from European registries by ESHRE: the European IVF monitoring Consortium (EIM) for the European Society of Human Reproduction and Embryology (ESHRE). Hum Reprod. 2018;33(9);1586-601. doi: 10.1093/humrep/dey242

(11)Dyer S, Chambers GM, De Mouzon J, et al. International Committee for Monitoring Assisted Reproductive Technologies world report: assisted reproductive technology 2008, 2009 and 2010. Hum Reprod. 2016:31(7):1588-609. doi: 10.1093/humrep/dew082

(12)Lafuente-Funes S. Shall we stop talking about egg donation? Transference of reproductive capacity in the Spanish bioeconomy. Biosocieties [Internet]. 2019 April [cited 2019 Sep 30]. Available from: https://doi.org/10.1057\%2Fs41292-019-00149-5

(13)Herbrand C, Hudson N. Mitochondrial donation: a new solution for infertility in the reproductive bioeconomy? Paper presented at: 4S conference, 2019 Sept 4-7; New Orleans, USA.

(14)Culley L, Hudson N, Rapport F, Blyth E, Norton W, Pacey AA. Crossing borders for fertility treatment: motivations, destinations and outcomes of UK fertility travellers. Hum Reprod. 2011;26(9);2373-81. doi: 10.1093/humrep/der191 
(15)Esposti SD, Pavone V. Oocyte provision as a (quasi) social market: insights from Spain. Soc Sci Med [Internet]. 2019 Aug [cited 2019 Aug 1];234;112381. Available from:

https://doi.org/10.1016/j.socscimed.2019.112381

(16)Keehn J, Holwell E, Abdul-Karim R, et al. Recruiting egg donors online: an analysis of in vitro fertilization clinic and agency websites' adherence to American Society for Reproductive Medicine guidelines. Fertil Steril. 2012;98(4);995-1000. doi: 10.1016/j.fertnstert.2012.06.052

(17)Holwell E, Keehn J, Leu CS, Sauer MV, Klitzman R. Egg donation brokers: an analysis of agency versus in vitro fertilization clinic websites. J Reprod Med. 2014;59(11-12);534-41.

(18)Baldwin K, Culley L, Hudson N, Mitchell H. Running out of time: exploring women's motivations for social egg freezing. J Psychosom Obstet Gynaecol. 2019;40(2);166-73. doi: 10.1080/0167482X.2018.1460352

(19)Carroll K, Kroløkke C. Freezing for love: enacting 'responsible' reproductive citizenship through egg freezing. Cult Health Sex. 2018;20(9);992-1005. doi: 10.1080/13691058.2017.1404643

(20)Waldby C. 'Banking time': egg freezing and the negotiation of future fertility. Cult Health Sex. 2015;17(4);470-82. doi: 10.1080/13691058.2014.951881

(21)Argyle CE, Harper JC, Davies MC. Oocyte cryopreservation: where are we now? Hum Reprod Update. 2016;22(4);440-9. doi: 10.1093/humupd/dmw007

(22)Cobo A, Domingo J, Pérez S, Crespo J, Remohí J, Pellicer A. Vitrification: an effective new approach to oocyte banking and preserving fertility in cancer patients. Clin Trans/ Oncol. 2008;10(5);268-73. doi: 10.1007/s12094-008-0196-7

(23)Shenfield F, De Mouzon J, Scaravelli G, et al. Oocyte and ovarian tissue cryopreservation in European countries: statutory background, practice, storage and use. Hum Reprod Open. 2017; 17; hox003. doi: 10.1093/hropen/hox003

(24)Human Fertilisation and Embryology Authority. Egg freezing in fertility treatment: trends and figures 2010-2016 [Internet]. Human Fertilisation and Embryology Authority; 2018 [cited 2019 Sep 30]. Available from: https://www.hfea.gov.uk/media/2656/egg-freezing-in-fertility-treatment-trendsand-figures-2010-2016-final.pdf

(25)Registro Nacional de Actividad 2017-Registro SEF. Informe estadístico de técnicas de reproducción asistida 2017. Ministerio de Sanidad, Consumo y Bienestar Social; 2017 [cited 2020 Feb 24]. Available from: https://www.registrosef.com/public/docs/sef2017_IAFIVm.pdf

(26)Hudson N, Coveney C, Herbrand C, et al. Representing 'altruistic donation' in Europe: an analysis of fertility clinic websites in the UK, Belgium and Spain. Paper presented at: British Sociological Association annual conference; Deconstructing Donation Study Group; 2017 Dec 7; Bristol, England.

(27)Keehn J, Howell E, Sauer MV, Klitzman R. How agencies market egg donation on the internet: a qualitative study. J Law Med Ethics. 2015;43(3);610-18. doi: 10.1111/jlme.12303

(28)Klitzman R. Buying and selling human eggs: infertility providers' ethical and other concerns regarding egg donor agencies. BMC Med Ethics [Internet]. 2016 Nov [cited 2019 Aug 1];17(71). Available from: https://doi.org/10.1186/s12910-016-0151-z

(29)Quaas AM, Pennings G. The current status of oocyte banks: domestic and international perspectives. Fertil Steril. 2018;110(7);1203-8. doi:10.1016/j.fertnstert.2018.07.013

(30)Kool EM, Bos AME, Van Der Graaf R, Fauser BCJM, Bredenoord AL. Ethics of oocyte banking for third-party assisted reproduction: a systematic review. Hum Reprod Update. 2018;24(5);615-35. doi: 0.1093/humupd/dmy016 
(31)Quaas AM, Melamed A, Chung K, Bendikson MD, Paulson RJ. Egg banking in the United States: current status of commercially available cryopreserved oocytes. Fertil Steril. 2013;99(3);827-31. doi: 10.1016/j.fertnstert.2012.10.047

(32)Akin JW, Bell KA, Thomas D, Boldt J. Initial experience with a donor egg bank. Fertil Steril. 2007:88(2);497. doi: 10.1016/j.fertnstert.2006.11.058

(33)Millbank J. The role of professional facilitators in cross-border assisted reproduction. Reprod Biomed Soc Online. 2018;6;60-71. doi: 10.1016/j.rbms.2018.10.013

(34)Ravelingien A, Provoost V, Pennings G. Creating a family through connection websites and events: ethical and social issues. Repro Biomed Online. 2016;33(4);522-8. doi: 10.1016/j.rbmo.2016.07.004

(35)Commission Directive 2006/17/EC of 8 February 2006 implementing Directive 2004/23/EC of the European Parliament and of the Council as regards certain technical requirements for the donation, procurement and testing of human tissues and cells. Official Journal of the European Union L 38/40.

(36)Dondorp W, De Wert G, Pennings G, et al. ESHRE Task Force on Ethics and Law 21: genetic screening of gamete donors: ethical issues. Hum Reprod. 2014:29(7);1353-59. doi: 10.1093/humrep/deu111

(37)BBC News. Denmark tightens sperm donor law after NF1 transmission [internet]. 2012 [cited 2019 Sep 30]. Available from: https://www.bbc.co.uk/news/world-europe-19711565

(38)Mertes H, Lindheim SR, Pennings G. Ethical quandaries around expanded carrier screening in third-party reproduction. Fertil Steril. 2018;109(2);190-4. doi: 10.1016/j.fertnstert.2017.11.032

(39)Lazarin GA, Haque IS. Expanded carrier screening: a review of early implementation and literature. Semin Perinatol. 2016;40(1);29-34. doi: 10.1053/j.semperi.2015.11.005

(40)Vaz-de-Macedo C, Harper J. A closer look at expanded carrier screening from a PGD perspective. Hum Reprod. 2017;32(10);1951-56. doi: 10.1093/humrep/dex272

(41)Franklin S. Biological relatives: IVF, stem cells, and the future of kinship. Durham: Duke University Press; 2013.

(42)Lenk C, Beier K. Is the commercialisation of human tissue and body material forbidden in the countries of the European Union? J Med Ethics 2012; 38; 342-346 doi: 10.1136/jme.2010.038760 